\title{
Using self-organising maps to explore ozone profile validation results - SCIAMACHY limb compared to ground-based lidar observations
}

\author{
J. A. E. van Gijsel et al.
}

Correspondence to: J. A. E. van Gijsel (anne.van.gijsel@knmi.nl) 
This document contains the scatter plots of the most relevant explanatory variables versus the codebook values at selected altitudes. These scatter plots complement the discussion of Fig. 8 .

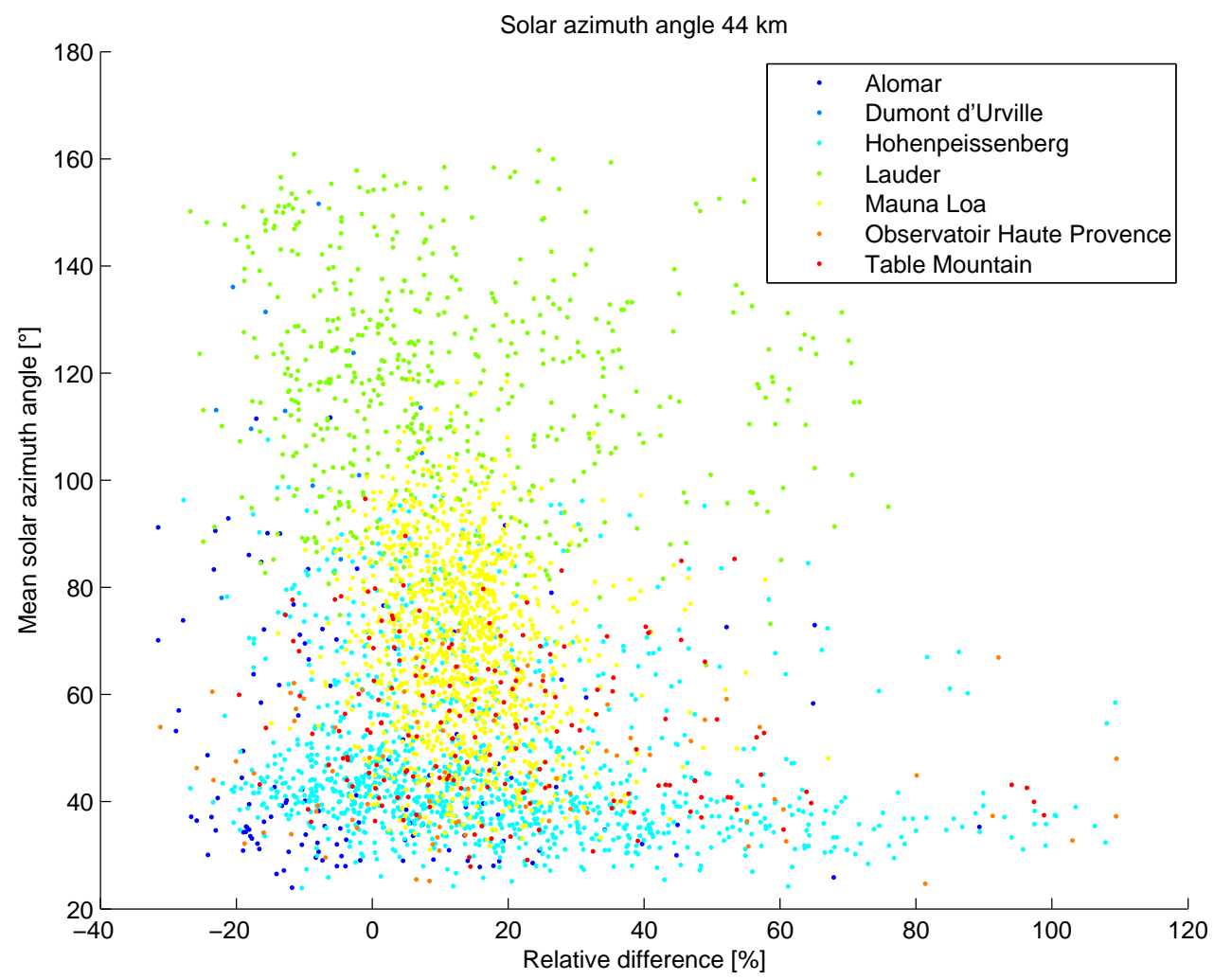

Figure S1. Mean solar azimuth angle $\left[{ }^{\circ}\right]$ versus the de-normalised codebook values $[\%]$ of the altitude of $44 \mathrm{~km}$. Colours indicate collocated lidar site. 


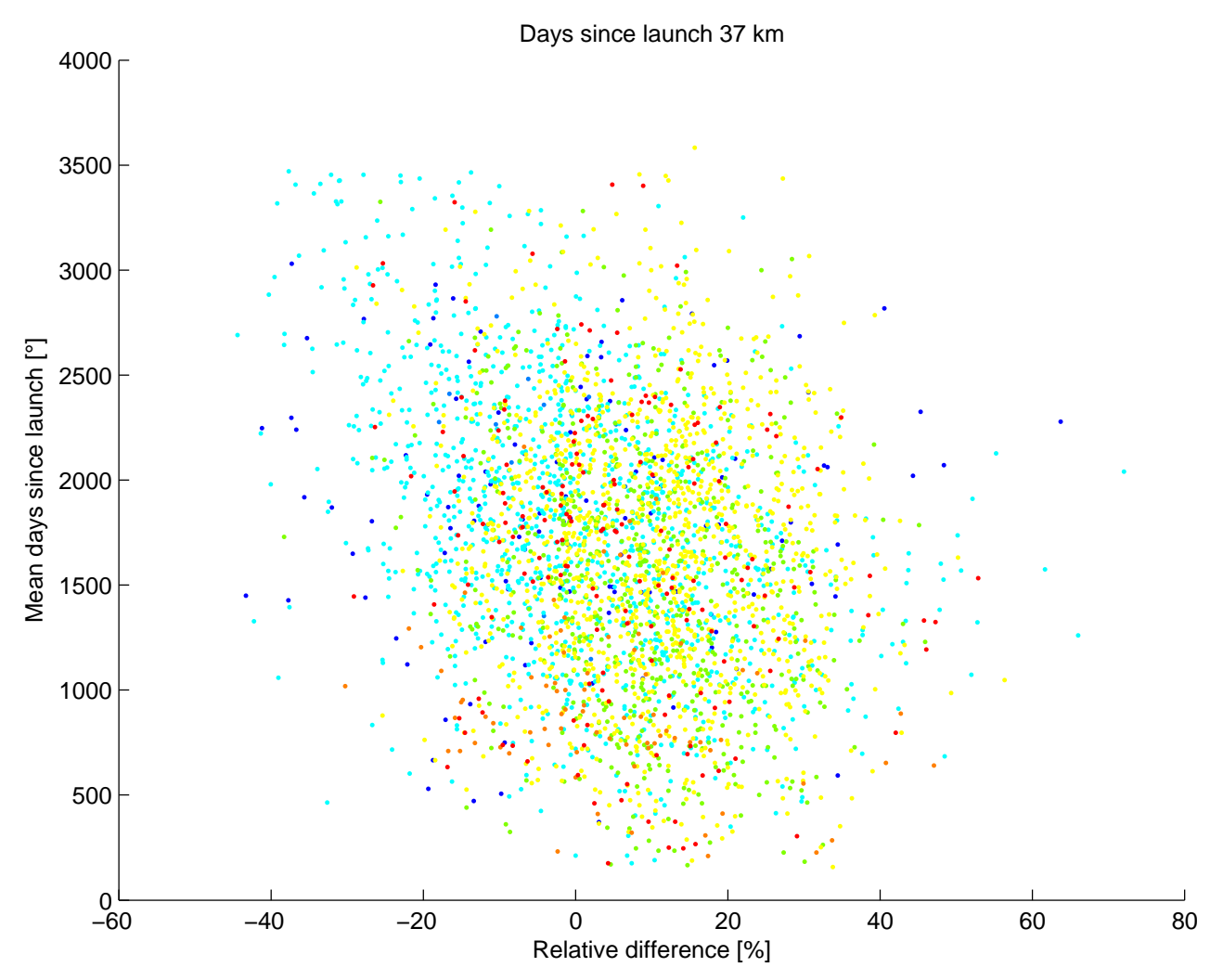

Figure S2. Mean number of days since launch [days] versus de-normalised codebook [\%] at an altitude of $37 \mathrm{~km}$. Colours indicate collocated lidar site as in Fig. S1. 

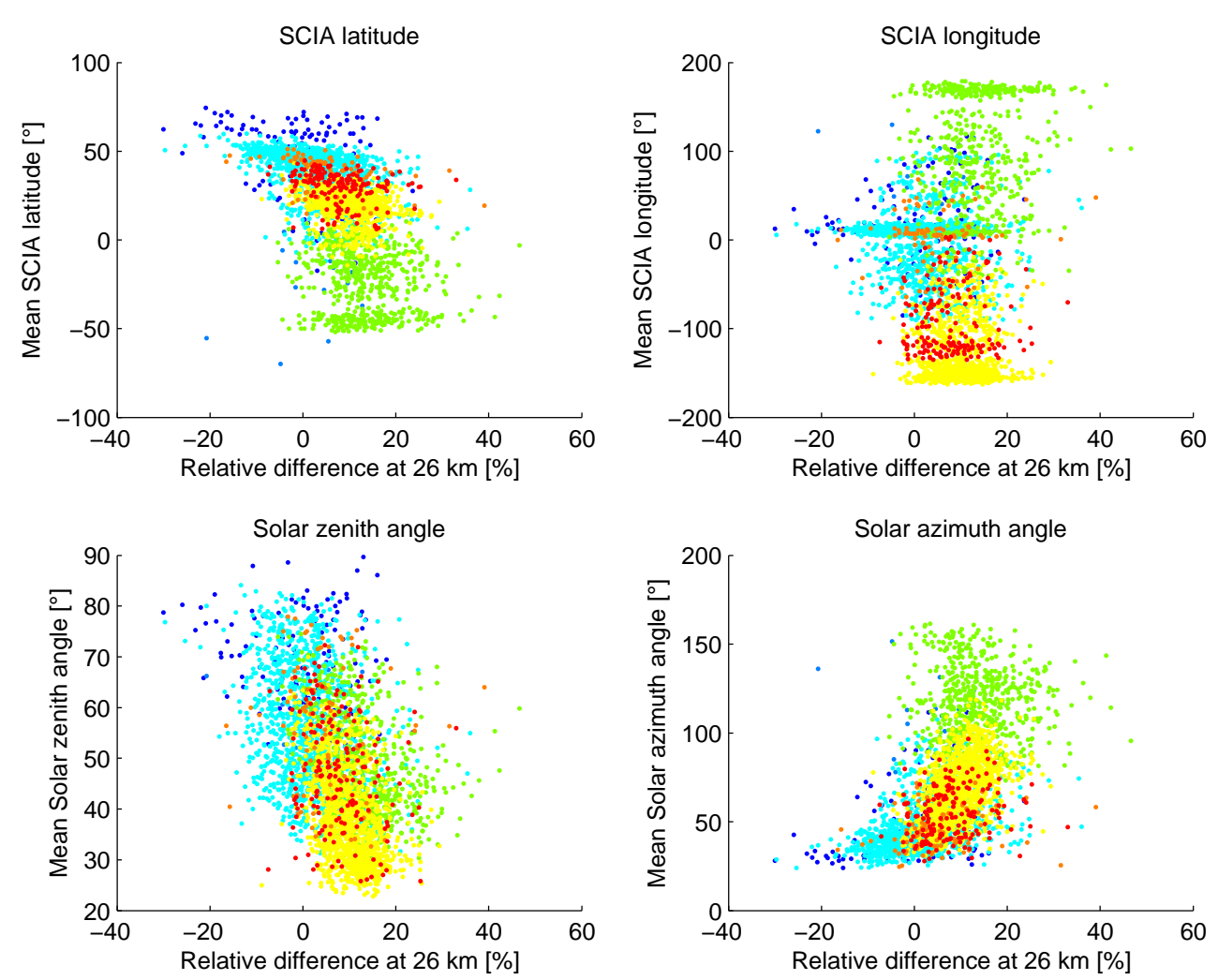

Figure S3. De-normalised codebook vector [\%] of the altitude $26 \mathrm{~km}$ versus the mean SCIAMACHY latitude $\left[{ }^{\circ}\right]$ (top left), mean SCIAMACHY longitude $\left[^{\circ}\right]$ (top right), mean solar zenith angle $\left[{ }^{\circ}\right]$ (bottom left), mean solar azimuth angle $\left[^{\circ}\right]$ (bottom right). The collocated lidar sites can be distinguished by the colours (as indicated in Fig. S1). 


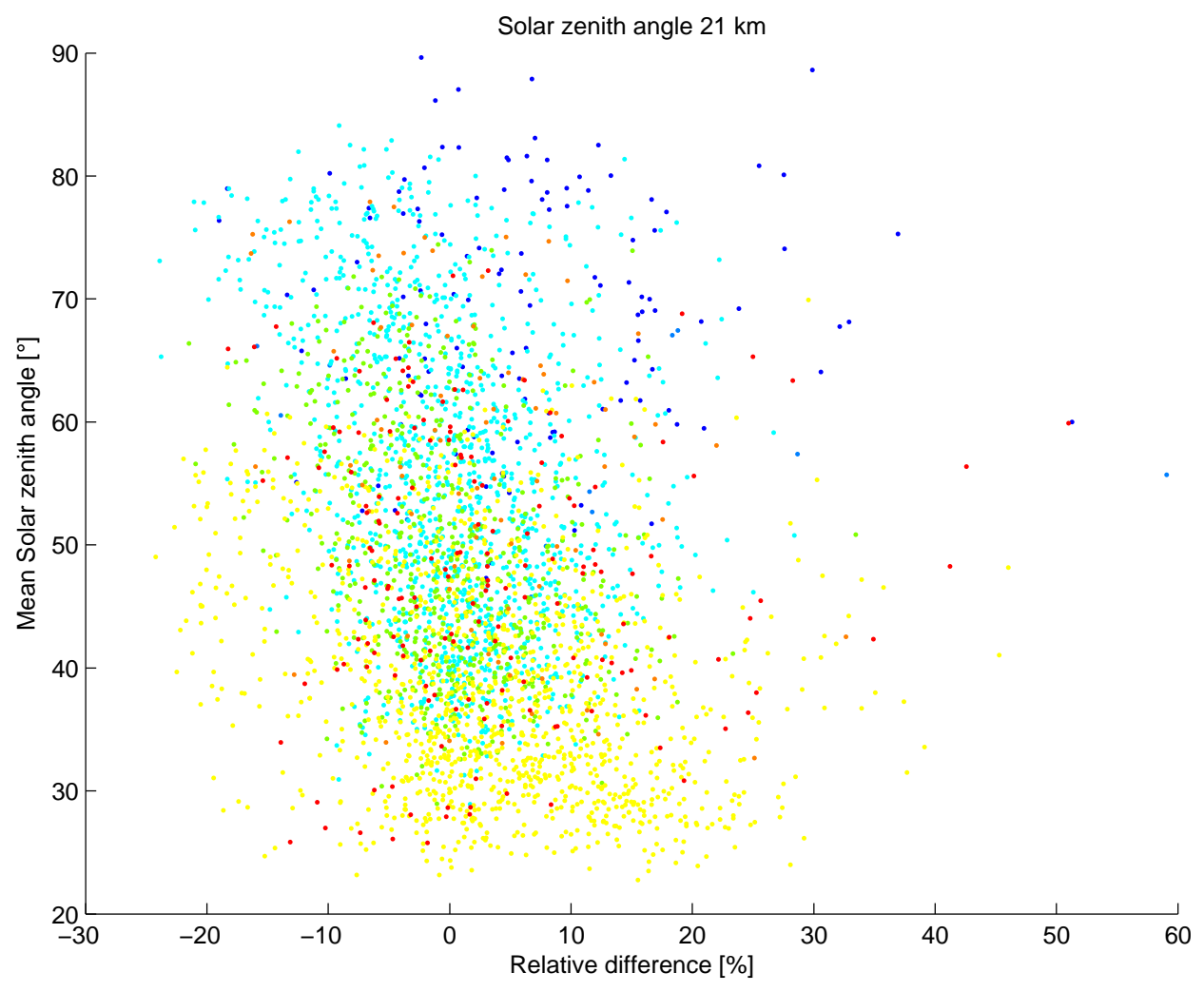

Figure S4. De-normalised codebook [\%] of the altitude $21 \mathrm{~km}$ versus mean solar zenith angle $\left.{ }^{\circ}\right]$. Colours indicate collocated lidar site (as in Fig. S1). 


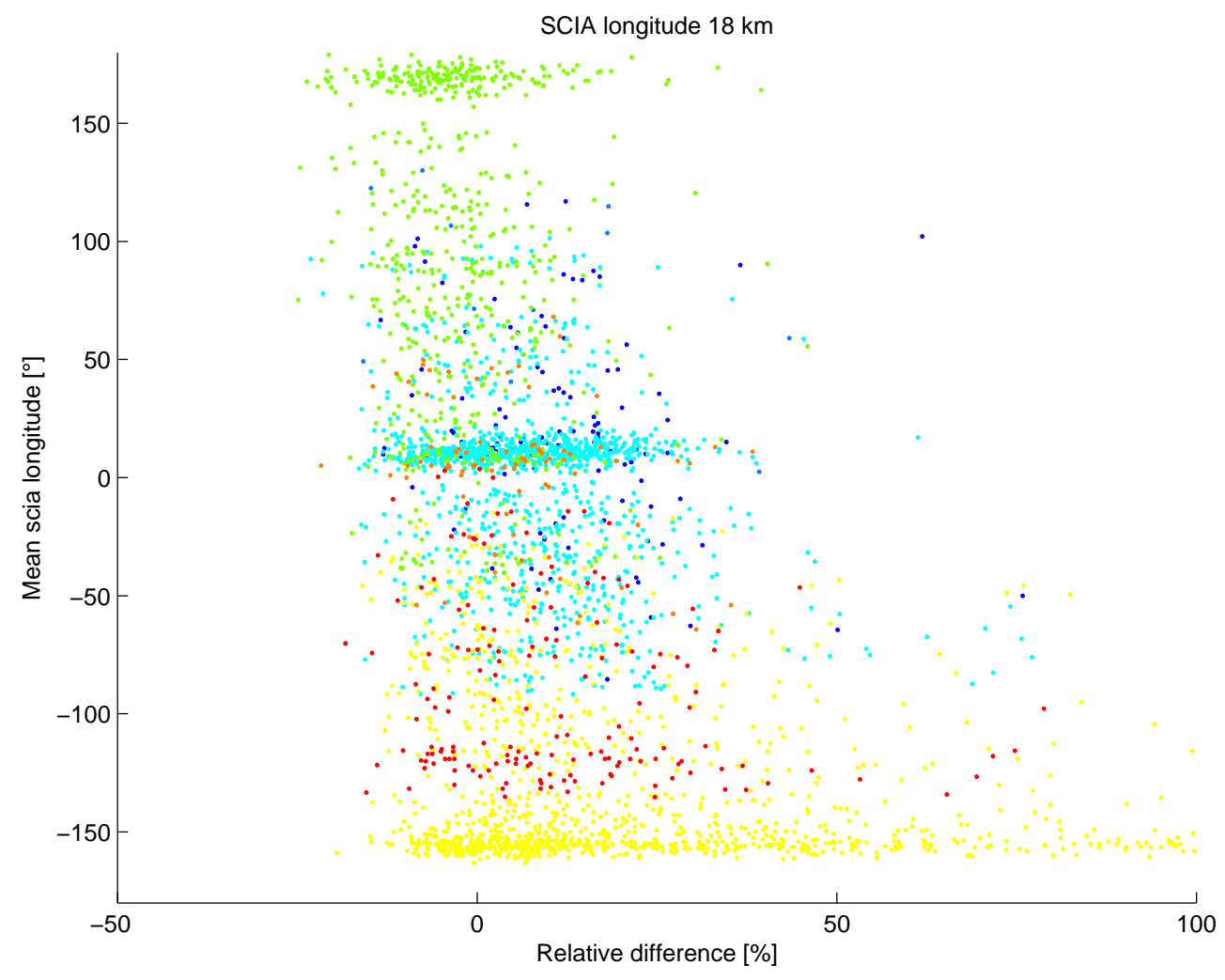

Figure S5. De-normalised codebook of the altitude $18 \mathrm{~km}$ versus mean SCIAMACHY longitude $\left[{ }^{\circ}\right]$. Plot view is limited to maximum differences of $100 \%$. Colours indicate the collocated lidar site (see Fig. S1). 